knowledge of the English language. These people do not subscribe for magazines and will more carefully peruse the drug-store paper, than the average American who devotes his time to reading the weekly or monthly publications containing stories by highly paid authors.

Window Display's:-These that attract attention require considerable thought and study. The average person goes along engrossed with his own thoughts and it takes something unusual to divert his mind from himself to the windows. We spend considerable time on this feature of our advertising.

Gifts:-At regular intervals we give away, with every purchase of twenty-five cents or over, a gift of some sort, usually a small bottle of perfune. This creates a feeling of friendliness and good-will.

Personal Adzertising:-The biggest factor in dealing with this class, is what I would term, personal advertising. By this I mean the treatment of the customer while in the store. People who are ignorant and often poorly-clad, seldom receive courteous attention, therefore they appreciate it all the more when they do. We try to make our customers feel at home and treat them with consideration. I have impressed upon my clerks, that it is the customer who pays their salaries, the rent and my profits.

Special Mcthods:-One of the things my customers need, but few use, is a good tooth brush and a tooth powder. To acquaint them with their needs in this direction, I have printed small slips of paper in three languages, English, Polish and Italian. I dwell upon the necessity of keeping the teeth clean in order to preserve them, and save dental bills. By this means $\mathrm{I}$ am rendering them a real service and at the same time promoting the sale of my goods.

I believe in specializing on one preparation or product. In having something a little better than any one else, if possible. I give special care to the handling of cod liver oil, importing it direct from Norway. I see to it that it is always fresh and sweet. This I advertise as a leader, not in price but in quality, in the Scandinavian papers.

As you see my methods are neither new or startling, but I trust that my paper will be of interest to those engaged in the drug business under similar conditions, or to those engaged in the drug business under different conditions who have made a study of their possibilities.

\title{
WHAT IS YOUR BEST PAYING SIDE LINE?
}

\section{FRA.VK RICHARDSON.}

My best paying side line was for a long time taken as a matter of course and not much attention paid to it.

But after a time my attention was called to the possibilitics in the cigar department, and I began to take notice, purchased a first class case with lots of moistening surface and a hygrometer, to keep me informed as to the condition of the atmosphere in the case.

Care was taken in selecting first-class brands at the various prices, and then we got behind the goods and began to "boost." 
We were careful to keep the moisture in the case between 60-65 degrees, keeping the case tightly closed when not in use, consequently the stock is always in perfect condition and now we have the reputation of being the only store in town, whose stock is not all dried out during the winter time, this, of course, has helped the trade greatly and the cigar department has grown until it is the best paying side line in the store, doing nearly three times the business it did before. During the winter months, when your store is heated by artificial heat, cigars and tobacco must be watched very carefully and a certain degree of moisture (6065) maintained in the case constantly, lest your stock dry out, lose its flavor and your trade go elsewhere, where the stock is properly kept.

I figure that my cigar department pays my rent, light and heat, and that is doing pretty well in a town of 1600 with 15 places selling cigars and one cigar manufacturer.

Too little attention is paid to this department in the average store, the stock is purchased, placed in the case and no further attention given it except to hand out the goods when called for.

Cigars are very sensitive to artificial heat and quickly dry out and lose their flavor and can not be brought back to their original condition. A little thought and attention will prevent this. In the first place get a good tight case, with plenty of moistening surface, place a hygrometer in it, and then see to it that the moisteners are filled at least once a week or as often as the hygrometer falls below 60 degrees; and keep the case tightly closed when not selling from it.

Have variety enough to suit all classes of customers, and endeavor to learn the likes and dislikes of your customers.

When you put in a new brand show it up and pass out enough samples to start a demand for it.

In a community such as the one I live in, special sales and premiums do not pay, but by careful attention to keeping stock, giving good value, and a pleasant word to the customer any one can largely increase the trade in this department, without adding to the expense account.

EFFICIENCY AND A NINE HOUR DAY.

C. A. WEAVER, PH. C.

In taking up this subject of shorter hours for the Retail Druggist, I have been led to believe, from an experience of some twenty-eight years, behind the counter, that the working of long hours was an unnecessary hardship that could be easily avoided.

This paper is written from the view-point of the so-called "two-man" drug store, comprising a registered proprietor, and one registered clerk, which I believe, constitutes about 60 per cent. of all the drug stores of the United Statesstores doing a business of from fifteen to thirty thousand dollars a year. The smaller amount representing the two-man store, with the limited territory and 